\title{
RESEARCH
}

Open Access

\section{The glucose infusion rate of parenteral nutrition in the first week of life in preterm infants: an observational study}

\author{
Dina Angelika ${ }^{1,2}$, Risa Etika ${ }^{2 *}$, Martono Tri Utomo ${ }^{2}$, Setya Mirha ${ }^{3}$, Kartika Darma Handayani ${ }^{2}$ and
} I. Dewa Gede Ugrasena²

\begin{abstract}
Background: Most preterm infants require a continuous glucose infusion in the early postnatal period due to the interruption of the transplacental glucose supply after birth to promote better neurodevelopmental outcomes.

Aims: To investigate the glucose infusion rate (GIR) on parenteral nutrition (PN) in the first week of life administered in preterm infants and its effect on neonatal morbidity and mortality.

Methods: This study included 97 infants aged $<37$ gestational weeks and weighed $<2500 \mathrm{~g}$ at birth. Infants recruited in this study were classified into 3 groups based on the GIR usage in parenteral nutrition as follows: GIR usage of $5-<7 \mathrm{~g} / \mathrm{kg} /$ day (Group I), GIR usage of $7-13 \mathrm{~g} / \mathrm{kg} /$ day (Group II), and GIR usage of $>13-15 \mathrm{~g} / \mathrm{kg} /$ day (Group III). Univariate and multivariate logistic regression analyzes were carried out to investigate whether the GIR usage in the three groups was associated with selected neonatal morbidities and mortality. Neonatal morbidities analyzed included respiratory distress syndrome (RDS), necrotizing enterocolitis, sepsis, retinopathy of prematurity, pulmonary hypertension, hypoglycemia, and hyperglycemia.

Result: Of 97 preterm infants included, 51.5\% infants had a gestational age of $34-<37$ weeks, and $54.6 \%$ infants had a birth weight of 1500-<2500 g. The multivariate logistic regression analysis showed that the GIR usage of 5$<7 \mathrm{~g} / \mathrm{kg} /$ day was an independent variable that significantly increased the risk of hypoglycemia (Adjusted Odds Ratio $[A O R]=4.000,95 \%$ Confidence Interval $[C I]=1.384-11.565, P=0.010)$ and reduced the risk of sepsis $(A O R=$ $0.096,95 \% \mathrm{Cl}=0.012-0.757, P=0.026$ ). The GIR usage in all three groups did not increase the risk of mortality. For neonatal morbidity analyzed in this study, $\operatorname{RDS}(A O R=5.404,95 \% \mathrm{Cl}=1.421-20.548, P=0.013)$ was an independent risk factor of mortality.
\end{abstract}

Conclusion: The GIR usage of $<7 \mathrm{~g} / \mathrm{kg} / \mathrm{day}$ in PN in the first week of life administered to preterm infants was an independent variable in increasing hypoglycemia, but in contrast, reducing the risk of sepsis.

Keywords: Parenteral nutrition, Glucose infusion rate, Morbidity, Mortality, Preterm infant

\footnotetext{
* Correspondence: neonatologi.soetomo@gmail.com

${ }^{2}$ Department of Child Health, Faculty of Medicine, Universitas Airlangga - Dr. Soetomo General Academic Hospital, Jl. Mayjend Prof. Dr. Moestopo No. 6-8, Airlangga, Gubeng, Surabaya, East Java 60286, Indonesia

Full list of author information is available at the end of the article
}

(c) The Author(s). 2021 Open Access This article is licensed under a Creative Commons Attribution 4.0 International License, which permits use, sharing, adaptation, distribution and reproduction in any medium or format, as long as you give appropriate credit to the original author(s) and the source, provide a link to the Creative Commons licence, and indicate if changes were made. The images or other third party material in this article are included in the article's Creative Commons licence, unless indicated otherwise in a credit line to the material. If material is not included in the article's Creative Commons licence and your intended use is not permitted by statutory regulation or exceeds the permitted use, you will need to obtain permission directly from the copyright holder. To view a copy of this licence, visit http://creativecommons.org/licenses/by/4.0/. The Creative Commons Public Domain Dedication waiver (http://creativecommons.org/publicdomain/zero/1.0/) applies to the data made available in this article, unless otherwise stated in a credit line to the data. 


\section{Introduction}

The early postnatal period is a critical phase for preterm infants due to interruption of transplacental nutrient transfer which requires adequate protein and energy intake from the beginning of birth to optimize long-term growth [1]. Parenteral nutrition (PN) is recommended for preterm infants who may not tolerate enteral feeding in the first few postnatal days, are critically ill and growing, have impaired bowel function due to diseases such as necrotizing enterocolitis, and have congenital anatomic gastrointestinal abnormalities [2, 3].. The significant improvements of $\mathrm{PN}$ in preterm infants developed in recent years resulted in more preterm infants survived and reduced poor neurodevelopmental outcomes [4]. The current provision of $\mathrm{PN}$, referred to as earlyaggressive $\mathrm{PN}$, provides the administration of protein and energy at higher concentrations than the previous conventional PN, has been adopted as a standard service for neonatal care in many countries [5]. This PN practice must be administered directly after birth which aims to promote optimal plasma glucose levels and to ensure a positive energy balance [6]

As much as $60 \%$ of preterm infants require a continuous glucose infusion immediately after birth to maintain blood glucose levels $[7,8]$. The glucose infusion rate (GIR) at parenteral nutrition in preterm infants should be maintained at $6-8 \mathrm{mg} / \mathrm{kg} / \mathrm{min}$ to ascertain adequate glucose requirements $[4,7]$. Some literature provides recommendations for glucose administration of $\mathrm{PN}$ in preterm infants with various GIRs in expressing carbohydrate intakes such as GIR of $8-12 \mathrm{~g} / \mathrm{kg} /$ day [4], GIR of $6-15 \mathrm{~g} / \mathrm{kg} /$ day [9], or GIR of $8-18 \mathrm{~g} / \mathrm{kg} /$ day [10]. However, in earlyaggressive PN, the GIR is enhanced to as high as 18 $\mathrm{g} / \mathrm{kg} /$ day of glucose to attain optimal nutritional support which aims to improve growth and development outcome $[9,11]$. A study conducted by Tottman et al. reported that decreasing carbohydrate intake of parenteral nutrition in preterm infants to $10.1 \mathrm{~g} / \mathrm{kg} /$ day reduced the risk of neonatal hyperglycemia [12].

Either higher or lower glucose intake has a positive correlation with mortality $[13,14]$ and neonatal morbidity including respiratory distress syndrome (RDS) [15], necrotizing enterocolitis (NEC) [16], sepsis [17], retinopathy of prematurity (ROP) [18], pulmonary hypertension (PH) [19], hypoglycemia [20], and hyperglycemia [21]. Based on the description above, how much the glucose supply is optimal to provide a better outcome in preterm infants receiving parenteral nutrition is unclear and the results of related studies are conflicting $[12,13]$. Therefore, this study aimed to investigate the GIR on PN in the first week of life administered in preterm infants and its effect on neonatal morbidity and mortality.

\section{Methods}

\section{Study background and ethical approval}

This observational cohort study was conducted in the neonatal intensive care unit (NICU) at Dr. Soetomo General Academic Hospital, Surabaya, Indonesia between April 2018 and May 2019. The sample size was calculated based on the formulation from Hulley et al. [22] with the following formula: an expected proportion of 0.5 , a desired total width of 0.2 , and a confidence interval (CI) of 95\%; therefore, the calculation result was 97 samples. The study flow chart of subject recruitment was available in Fig. 1. Clinical data for each infant in this study were obtained through medical records.

This study was approved by the Ethical Committee in Health Research at the Dr. Soetomo General Academic Hospital (Reference number. 0203/KEPK/IV/2018). Informed and signed consent was acquired from the parents or authorized representatives of each infant.

\section{Participant eligibility}

All preterm infants admitted to the NICU of the Dr. Soetomo General Hospital between April 2018 and May 2019 and receiving parenteral nutrition beginning on the first day of life were enrolled in this study. The exclusion criteria were: 1) being born outside this hospital, 2) receiving postnatal steroids and/or methylxanthine [15, $23], 3)$ having any major congenital anomaly [21], 4) being discharged from hospital in less than 7 days old, 5) the parents did not provide consent, or 6) infants were withdrawn from the study by their parents.

The risk of hypoglycemia due to prematurity or low birth weight and perinatal asphyxia could be considered as confounding factors that could influence the results of this study. Therefore, to control the risk of hypoglycemia due to prematurity or low birth weight, all samples in the study were preterm infants, in addition, the blood glucose (BG) levels analyzed were BG levels during PN. In controlling for asphyxia, the pediatric residents who were in charge of helping the infant during delivery were doctors trained in neonatal resuscitation.

Participants recruited in this study were classified into 3 groups based on the use of GIR in parenteral nutrition as follows: GIR of $5-<7 \mathrm{~g} / \mathrm{kg} /$ day (Group I), GIR of $7-$ $13 \mathrm{~g} / \mathrm{kg} /$ day (Group II), and GIR of $>13-15 \mathrm{~g} / \mathrm{kg} /$ day (Group III) $[9,11]$. The GIR value analyzed in this study was the highest GIR value given to each infant during the administration of parenteral nutrition in the first week of life. The study was conducted during the administration of parenteral nutrition in the first week of life.

\section{Nutrition protocol}

All infants received PN according to the standard protocol in our NICU beginning on the first day of life. Intravenous amino acids (Aminosteril Infant; Fresenius Kabi, 

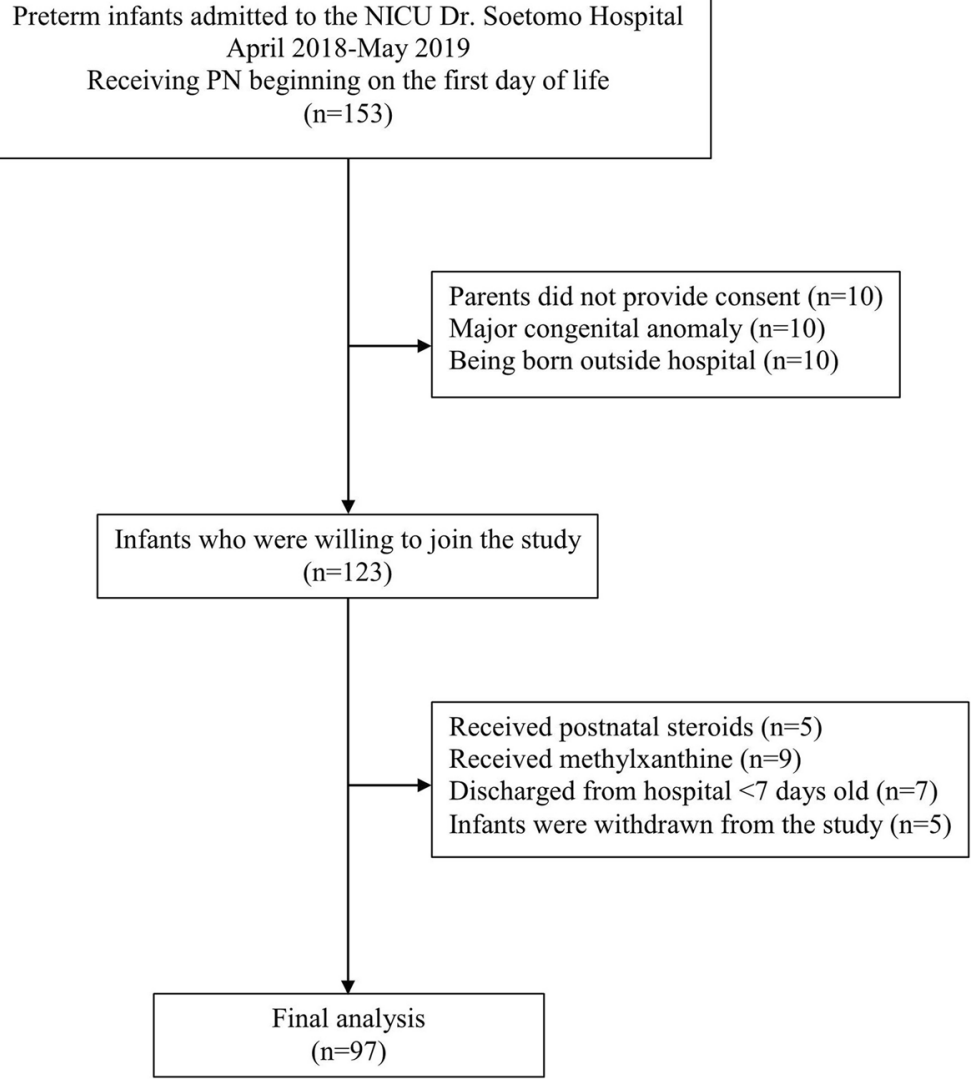

Fig. 1 The study flow chart of participant recruitment

Bad Homburg, Germany) were started on the first day with a dose of $2 \mathrm{~g} / \mathrm{kg} /$ day and increased daily by $0.5 \mathrm{~g} /$ $\mathrm{kg} /$ day to $3.5 \mathrm{~g} / \mathrm{kg} /$ day [24].

Intravenous dextrose was administered with a GIR of at least $5 \mathrm{~g} / \mathrm{kg} /$ day. If the infants could tolerate that dosage, on the next day, the GIR was increased by $1-2 \mathrm{~g} / \mathrm{kg} /$ day adjusted based on daily fluid volume and BG level. The maximum GIR administered was $15 \mathrm{~g} / \mathrm{kg} /$ day. The administration of a GIR exceeding $15 \mathrm{~g} / \mathrm{kg} /$ day required careful consideration and discussion among supervisors. The BG level was maintained at a level of $45-150 \mathrm{mg} / \mathrm{dL}$. PN was administered via central venous access by 4 Fr polyvinyl chloride umbilical catheter (Vygon, Ecouen, France) or by $1 \mathrm{Fr} / 28 \mathrm{G}$ peripherally inserted central venous polyurethane catheter (Premicath; Vygon, Ecouen, France). When using peripheral venous access, the maximum concentration of dextrose administered is $12.5 \%$.

Intravenous lipids (Smoflipid 20\%; Fresenius Kabi, Bad Homburg, Germany) were administered starting with a dose of $1 \mathrm{~g} / \mathrm{kg} /$ day and increased daily by $0.5 \mathrm{~g} / \mathrm{kg} /$ day to $3 \mathrm{~g} / \mathrm{kg} /$ day [25]. Several electrolytes were provided including sodium (2-4 mmol/kg/day), potassium (1-2 $\mathrm{mmol} / \mathrm{kg} /$ day), magnesium $(0.1-0.3 \mathrm{mmol} / \mathrm{kg} /$ day $)$, calcium $(0.6-1.5 \mathrm{mmol} / \mathrm{kg} /$ day $)$, and phosphate $(0.7 \mathrm{mmol} /$ $\mathrm{kg} /$ day). Water-soluble vitamin (Soluvit $^{\circ} \mathrm{N}$; Fresenius Kabi, Bad Homburg, Germany) and fat-soluble vitamin (Vitalipid ${ }^{\circ}$ N; Fresenius Kabi, Bad Homburg Germany) were added to the PN solution at doses of $1 \mathrm{~mL} / \mathrm{kg} /$ day and $4 \mathrm{~mL} / \mathrm{kg} /$ day, respectively [26]. The total volume of fluid started at $80 \mathrm{~mL} / \mathrm{kg} /$ day, then increased daily by 10 $\mathrm{mL} / \mathrm{kg} /$ day for the first 3 days, then by $20 \mathrm{~mL} / \mathrm{kg} /$ day daily until the target volume reached $180 \mathrm{~mL} / \mathrm{kg} /$ day.

Enteral nutrition was given on the first day of life at a dose of $10 \mathrm{~mL} / \mathrm{kg} /$ day. If the infant tolerated this amount, the volume was increased by $20 \mathrm{~mL} / \mathrm{kg} /$ day. The infants received breast milk or preterm formula milk if breast milk was not available. PN was stopped when the enteral volume had reached $120 \mathrm{~mL} / \mathrm{kg} /$ day [27].

\section{Variables}

Clinical variables were collected including sex, gestational age, birth weight, mortality, and selected neonatal morbidity including RDS, NEC, sepsis, ROP, PH, hypoglycemia, and hyperglycemia. RDS was characterized by the presence of signs of respiratory distress shortly after birth and confirmed by the presence of a typical radiological appearance on chest radiographs [28]. NEC was confirmed by the appearance of 
pneumatosis intestinalis, pneumoperitoneum, or portal venous gas on an abdominal radiograph [29]. Neonatal sepsis was defined as the presence of clinical manifestations of infection accompanied by positive blood cultures [30]. ROP was confirmed according to indirect ophthalmoscopy [18]. PH was confirmed using echocardiography [19]. Hypoglycemia was defined as the BG level was less than $45 \mathrm{mg} / \mathrm{dL}$, whereas hyperglycemia was defined as the BG level was more than $150 \mathrm{mg} / \mathrm{dL}$ [20, 21].

\section{Data and statistical analysis}

Quantitative data were described using mean, median, range, minimum, maximum, and standard deviation (SD). Qualitative data were described using frequency and percentage. Intergroup comparisons were analyzed using Chi-Square tests or Kruskal-Wallis tests. The univariate analysis was carried out to investigate whether the GIR usage in the three groups was associated with selected neonatal morbidities and mortality. The multivariate logistic regression analysis was conducted to analyze which was the independent variable of the three GIR groups (Group I, Group II, and Group II) for each of selected neonatal morbidities (RDS, NEC, sepsis, ROP, PH, hypoglycemia, hyperglycemia) and mortality. Statistical analyzes were also performed to investigate the association between selected neonatal morbidities and mortality.

Univariate analysis was performed using the chisquare test. Multivariate logistic regression analysis was performed using a backward stepwise logistic regression model. Variables with a $P$-value $<0.05$ for adjusted odds ratio (AOR) of $95 \%$ confidence interval (CI) using multivariate logistic regression analysis were accepted as independent variables. All statistical analyses were performed using IBM SPSS Statistics 21 (IBM Corp., Armonk, NY, USA). A $P$ value $<0.05$ was considered to be statistically significant.

\section{Results}

\section{Characteristics of participants}

A total of 153 infants met the inclusion criteria and were included in this study. 10 parents did not provide consent, 10 infants were born outside this hospital, 5 infants received postnatal steroids, 9 infants received methylxanthine, 10 infants had a major congenital anomaly, 7 infants discharged from hospital $<7$ days old, and 5 infants were withdrawn from the study by their parents; therefore the data of 97 infants were analyzed. Of the 97 infants, the majority, 50 (51.5\%) infants had a gestational age of 34- < 37 weeks, and 53 (54.6\%) infants had a birth weight of $1500-<2500 \mathrm{~g}$. The infants in this study had a minimum gestational age of 27 weeks, maximum gestational age of 36 weeks, with a mean of 33 weeks, and an
SD of 2 weeks. The infants also had a minimum birth weight of $600 \mathrm{~g}$, a maximum birth weight of $2400 \mathrm{~g}$, a mean of $1564 \mathrm{~g}$, and an SD of $440 \mathrm{~g}$. As much as $74.2 \%$ of infants were delivered by cesarean section. Detailed characteristics of the infants recruited in this study were described in Table 1.

An analysis of infant characteristics based on the three groups as described in Table 2. There were no significant differences in sex, gestational age, birth weight, and mortality in the three groups. Meanwhile, in neonatal morbidity, there were significant differences in sepsis $(P=0.022)$ and hypoglycemia $(P=0.027)$ in the three groups.

\section{Distribution of the GIR values from day 1 to day 7}

The distribution of GIR values from day 1 to day 7 was described using the boxplot diagram in Fig. 2 as follows. The $\mathrm{X}$-axis described the time of the research which was conducted in days, from the first day to the seventh day.

Table 1 Characteristics of Participants

\begin{tabular}{|c|c|}
\hline Variables & n (\%) \\
\hline \multicolumn{2}{|l|}{ Gender } \\
\hline Male & $50(51.5)$ \\
\hline Female & $47(48.5)$ \\
\hline \multicolumn{2}{|l|}{ Gestational age } \\
\hline$<30$ weeks & $14(14.4)$ \\
\hline $30-<34$ weeks & $33(34.1)$ \\
\hline $34-<37$ weeks & $50(51.5)$ \\
\hline \multicolumn{2}{|l|}{ Birth weight } \\
\hline$<1000 \mathrm{~g}$ & $15(15.5)$ \\
\hline $1000-<1500 \mathrm{~g}$ & $29(29.9)$ \\
\hline $1500-<2000 \mathrm{~g}$ & $37(38.1)$ \\
\hline $2000-<2500 \mathrm{~g}$ & $16(16.5)$ \\
\hline \multicolumn{2}{|l|}{ Mode of delivery } \\
\hline Spontaneous & $25(25.8)$ \\
\hline Cesarean section & $72(74.2)$ \\
\hline \multicolumn{2}{|l|}{ Antenatal steroid } \\
\hline Yes & $39(40.2)$ \\
\hline No & $58(59.8)$ \\
\hline \multicolumn{2}{|l|}{ Outcome } \\
\hline Mortality & $17(17.5)$ \\
\hline Survive & $80(82.5)$ \\
\hline \multicolumn{2}{|l|}{ The use of GIR } \\
\hline Group I & $21(21.6)$ \\
\hline Group ॥ & $67(69.1)$ \\
\hline Group III & $9(9.3)$ \\
\hline
\end{tabular}

Data were shown as number and percentage

GIR, glucose infusion rate; Group I, the GIR usage of 5- $<7 \mathrm{~g} / \mathrm{kg} /$ day; Group II, the GIR usage of $7-13 \mathrm{~g} / \mathrm{kg} /$ day; Group III, the GIR usage of $>13-15 \mathrm{~g} / \mathrm{kg} /$ day 
Table 2 Characteristics of Infants Based on Glucose Infusion Rate

\begin{tabular}{|c|c|c|c|c|}
\hline \multirow[t]{2}{*}{ Variables } & \multicolumn{3}{|l|}{ GIR } & \multirow[t]{2}{*}{$p$} \\
\hline & $\begin{array}{l}\text { Group I } \\
\mathrm{n}(\%) \\
n=21\end{array}$ & $\begin{array}{l}\text { Gorup II } \\
\text { n (\%) } \\
n=67\end{array}$ & $\begin{array}{l}\text { Group III } \\
\mathrm{n}(\%) \\
n=9\end{array}$ & \\
\hline \multicolumn{5}{|l|}{ Gender } \\
\hline Male & $14(66.7)$ & $33(49.3)$ & $3(33.3)$ & \multirow[t]{2}{*}{0.196} \\
\hline Female & $7(33.3)$ & $34(50.7)$ & $6(66.7)$ & \\
\hline \multicolumn{5}{|l|}{ Gestational age } \\
\hline$<30$ weeks & $0(0.0)$ & $12(17.9)$ & $2(22.2)$ & \multirow[t]{3}{*}{0.179} \\
\hline $30-<34$ weeks & $6(28.6)$ & $24(35.8)$ & $3(33.3)$ & \\
\hline $34-<37$ weeks & $15(71.4)$ & $31(46.3)$ & $4(44.5)$ & \\
\hline \multicolumn{5}{|l|}{ Birth weight } \\
\hline$<1000 \mathrm{~g}$ & $1(4.7)$ & $12(17.9)$ & $2(22.2)$ & \multirow[t]{4}{*}{0.151} \\
\hline $1000-<1500 \mathrm{~g}$ & $6(28.7)$ & $21(31.3)$ & $2(22.2)$ & \\
\hline $1500-<2000 \mathrm{~g}$ & $13(61.9)$ & $20(29.9)$ & $4(44.5)$ & \\
\hline $2000-<2500 \mathrm{~g}$ & $1(4.7)$ & $14(20.9)$ & $1(11.1)$ & \\
\hline \multicolumn{5}{|l|}{ Outcome } \\
\hline Mortality & $1(4.7)$ & $13(19.4)$ & $3(33.3)$ & \multirow[t]{2}{*}{0.130} \\
\hline Survive & $20(95.3)$ & $54(80.6)$ & $6(66.7)$ & \\
\hline \multicolumn{5}{|l|}{ Neonatal morbidity } \\
\hline RDS & $10(47.6)$ & $37(55.2)$ & $4(44.5)$ & 0.728 \\
\hline NEC & $3(14.3)$ & $4(5.9)$ & $2(22.2)$ & 0.193 \\
\hline Sepsis & $1(4.7)$ & $22(32.8)$ & $4(44.5)$ & $0.022^{*}$ \\
\hline $\mathrm{ROP}$ & $3(14.3)$ & $7(10.4)$ & $0(0.0)$ & 0.498 \\
\hline Pulmonary hypertension & $3(14.3)$ & $5(7.5)$ & $1(11.1)$ & 0.630 \\
\hline Hypoglycemia & $9(42.9)$ & $11(16.4)$ & $1(11.1)$ & $0.027^{*}$ \\
\hline Hyperglycemia & $2(9.5)$ & $9(13.4)$ & $2(22.2)$ & 0.645 \\
\hline
\end{tabular}

Note: GIR, glucose infusion rate $(\mathrm{mg} / \mathrm{kg} / \mathrm{min}) ; \mathrm{RDS}$, respiratory distress syndrome; NEC, necrotizing enterocolitis; ROP, retinopathy of prematurity; *Significant $p$ value $<0.05$

The Y-axis represented the level of the glucose infusion rate which was defined in $\mathrm{g} / \mathrm{kg} /$ day. Day 1 , the median of GIR usage was 6.5 (range, 5-7) $\mathrm{g} / \mathrm{kg} /$ day. Day 2, the median of GIR usage was 7.5 (range, 5-11) g/ $/ \mathrm{kg} /$ day. Day 3, the median of GIR usage was 9 (range, 5-11.8) g/ $\mathrm{kg} /$ day. Day 4, the median of GIR usage was 10 (range, 5-13) $\mathrm{g} / \mathrm{kg} /$ day. Day 5, the median of GIR usage was 11 (range, 5-15) g/kg/day. Day 6, the median of GIR usage was 9.5 (range, $5-14$ ) g/ kg/day. Day 7 , the median of GIR usage was 8.5 (range, 5-14.2) g/ $\mathrm{kg} /$ day. The statistical test using the Kruskal-Wallis test showed that there was a significant difference in the GIR values in the three groups from day 1 to day $7(P<0.001)$.

The association between the GIR usage in the three groups with neonatal morbidities

Univariate and multivariate logistic regression analysis was carried out to investigate whether the GIR usage in the three groups was associated with selected neonatal morbidities including RDS, NEC, sepsis, ROP, pulmonary hypertension, hypoglycemia, and hyperglycemia in each group (Table 3 and Table 4). The GIR usage in both group II and group III did not have a significant association with selected morbidity. Meanwhile, the statistical result showed that there was a significant association between the GIR usage in group I and hypoglycemia (odds ratio $[\mathrm{OR}]=4.000,95 \% \mathrm{CI}=1.384-$ $11.565, P=0.008$ ). The multivariate logistic regression analysis in Table 4 showed that the GIR usage of 5-<7 $\mathrm{g} / \mathrm{kg} /$ day in a group I was a significant independent variable of increasing hypoglycemia risk (AOR $=4.000,95 \%$ $\mathrm{CI}=1.384-11.565, P=0.010)$ and reducing sepsis risk (AOR $=0.096,95 \% \mathrm{CI}=0.012-0.757, P=0.026$ ).

\section{The association between the GIR usage in the three groups and neonatal morbidities with mortality}

Univariate and multivariate logistic regression analysis was conducted to investigate the association between the GIR usage in the three groups and selected neonatal morbidities with mortality (Table 5 and Table 6). The statistical analysis showed that using a GIR of either GIR $5-<7 \mathrm{~g} / \mathrm{kg} /$ day, $7-13 \mathrm{~g} / \mathrm{kg} /$ day, or $>13-15 \mathrm{~g} / \mathrm{kg} /$ day did not increase the risk of mortality. In univariate analysis (Table 5), RDS $(\mathrm{OR}=5.423,95 \% \mathrm{CI}=1.446-20.346, P=$ $0.006)$ and sepsis $(\mathrm{OR}=3.875,95 \% \mathrm{CI}=1.306-11.495$, $P=0.011)$ increased the risk of mortality. While in multivariate logistic regression analysis (Table 6), RDS was an independent risk factor of mortality $(\mathrm{AOR}=$ $5.404,95 \% \mathrm{CI}=1.421-20.548, P=0.013)$.

\section{Discussion}

The significant improvement of nutritional strategies in preterm infants including early and aggressive parenteral nutrition resulted in more preterm infants survived and reduced detrimental outcomes [31]. Recently, the earlyaggressive parenteral nutrition strategy has been adopted as a standard service for neonatal care in many countries [4, 13]. Since 2012, our NICU has also carried out an early-aggressive parenteral nutrition strategy as part of standard services in neonatal care. Amino acids and lipids were administered from the first day of life at doses of $2 \mathrm{~g} / \mathrm{kg} /$ day and $1 \mathrm{~g} / \mathrm{kg} /$ day, respectively. For glucose administration, the GIR provided was $5-15 \mathrm{~g} / \mathrm{kg}$ per day which was adjusted based on daily fluid volume and BG level.

Glucose is the main source of non-protein calories in parenteral nutrition which is essential for the brain. The current parenteral nutrition management allows increasing the amount of glucose given to the infant while keeping the infant normoglycemic [6]. As much as $69.1 \%$ of preterm infants in this study received intravenous glucose with a GIR usage which was equivalent to a 


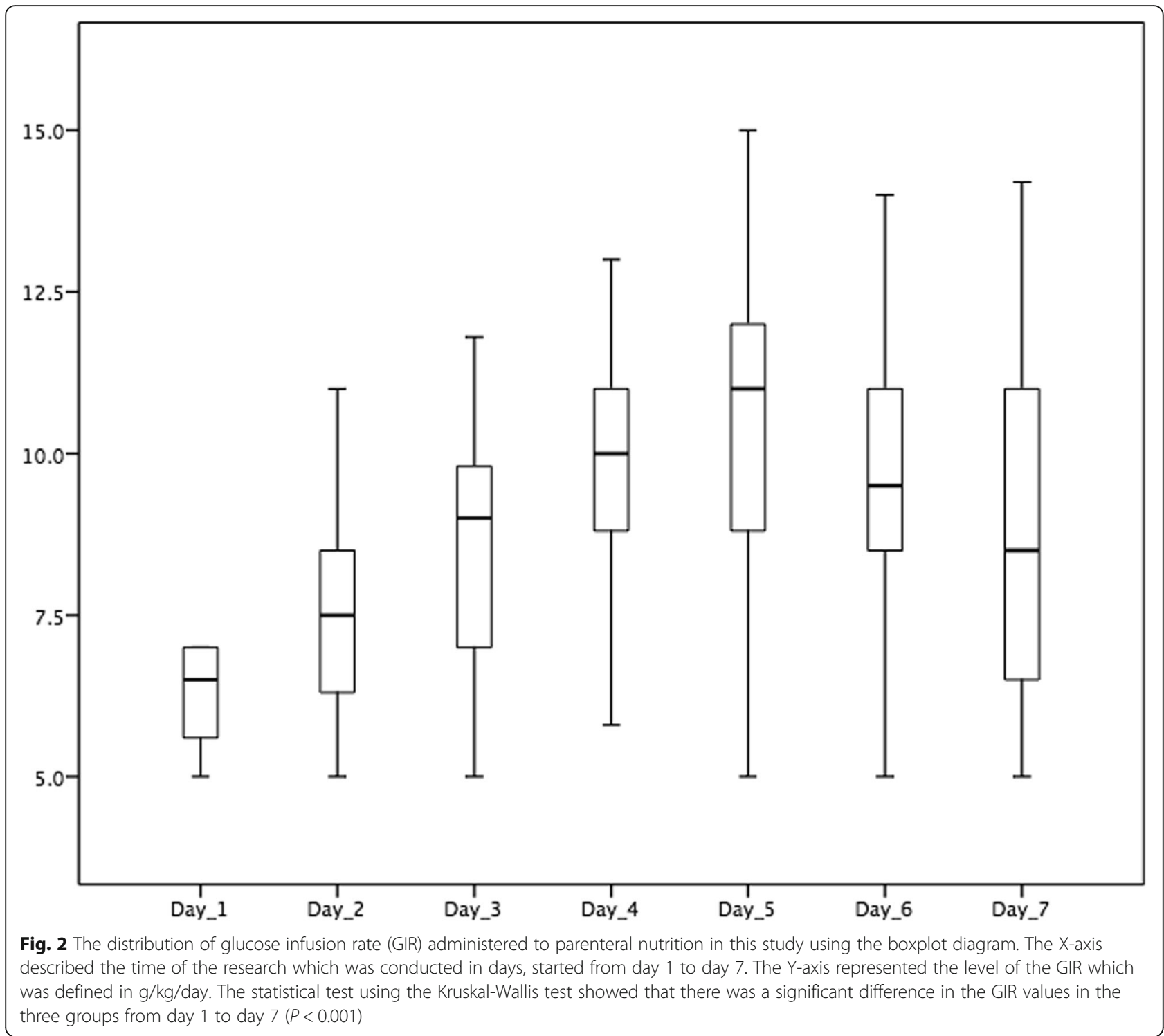

glucose supply of $7-13 \mathrm{~g} / \mathrm{kg} /$ day. The amount of glucose administered in this study was consistent with a study conducted by Stensvold et al. which promoted the provision of early-aggressive parenteral nutrition which provided a glucose supply of $8.5 \mathrm{~g} / \mathrm{kg} /$ day on the first day was then increased gradually to $15 \mathrm{~g} / \mathrm{kg} /$ day [13]. Another study demonstrated a lower glucose administration to reduce the risk of hyperglycemia with a glucose supply of $10.1 \mathrm{~g} / \mathrm{kg} /$ day in the first week [12]. However, some literature provides recommendations for administering glucose to PN with a wide variety of GIR such as GIR of $8-12 \mathrm{~g} / \mathrm{kg} /$ day [4], or higher GIRs such as GIR of $6-15 \mathrm{~g} / \mathrm{kg} /$ day [9] and GIR of $8-18 \mathrm{~g} / \mathrm{kg} /$ day [10]. The most likely explanation for this wide variation in GIR is that the value of the maximum glucose oxidase capacity is not completely known in neonates. The rate of glucose administration for parenteral nutrition should exceed the maximum glucose oxidase capacity, which in neonates is possibly as high as $18 \mathrm{~g} / \mathrm{kg} /$ day [11]. Furthermore, administration of the enteral route may support a lower GIR without risking hypoglycemia [12]. In this study, we did not quantify the amount of enteral nutrition; however, according to our protocol, we provided a minimum of enteral nutrition within $24 \mathrm{~h}$ after birth at a volume of $10 \mathrm{~mL} / \mathrm{kg} /$ day, if tolerated then the enteral intake was increased by $20 \mathrm{~mL} / \mathrm{kg} / \mathrm{d}$ until reaching 180 $\mathrm{mL} / \mathrm{kg} /$ day. PN was no longer administered when enteral nutrition reached a volume of $120 \mathrm{~mL} / \mathrm{kg} /$ day.

Further analysis was carried out to investigate whether the GIR correlated with neonatal morbidity. This study found that the GIR usage of $5-<7 \mathrm{~g} / \mathrm{kg} /$ day significantly increased the risk of hypoglycemia. An initially delivered glucose intake at the hepatic glucose production of 6-8 $\mathrm{mg} / \mathrm{kg} / \mathrm{min}$ [32] or $6-10 \mathrm{~g} / \mathrm{kg} /$ day [4] in early postnatal 
Table 3 Risk Factor of the three groups for selected Neonatal Morbidity

\begin{tabular}{|c|c|c|c|c|}
\hline GIR & n (\%) & OR & $95 \% \mathrm{Cl}$ & $p$ \\
\hline \multicolumn{5}{|l|}{ Group I } \\
\hline RDS & $10(47.6)$ & 0.776 & $0.295-2.043$ & 0.607 \\
\hline NEC & $3(14.3)$ & 1.944 & $0.443-8.538$ & 0.372 \\
\hline Sepsis & $1(4.7)$ & 0.096 & $0.012-0.757$ & 0.050 \\
\hline ROP & $3(14.3)$ & 1.643 & $0.386-6.994$ & 0.498 \\
\hline Pulmonary hypertension & $3(14.3)$ & 1.944 & $0.443-8.538$ & 0.372 \\
\hline Hypoglycemia & $9(42.9)$ & 4.000 & $1.384-11.565$ & $0.008^{*}$ \\
\hline \multicolumn{5}{|l|}{ Group II } \\
\hline RDS & $37(55.2)$ & 1.410 & $0.594-3.344$ & 0.435 \\
\hline NEC & $4(5.9)$ & 0.317 & $0.079-1.280$ & 0.093 \\
\hline Sepsis & $22(32.8)$ & 2.444 & $0.824-7.250$ & 0.101 \\
\hline ROP & $7(10.4)$ & 1.050 & $0.252-4.373$ & 0.947 \\
\hline Pulmonary hypertension & $5(7.5)$ & 0.524 & $0.130-2.109$ & 0.257 \\
\hline Hypoglycemia & $11(16.4)$ & 0.393 & $0.145-1.065$ & 0.062 \\
\hline Hyperglycemia & $9(13.4)$ & 1.009 & $0.285-3.575$ & 0.989 \\
\hline \multicolumn{5}{|l|}{ Group III } \\
\hline RDS & $4(44.5)$ & 0.698 & $0.176-2.774$ & 0.608 \\
\hline NEC & $2(22.2)$ & 3.306 & $0.574-19.043$ & 0.160 \\
\hline Sepsis & $4(44.5)$ & 2.261 & $0.559-9.151$ & 0.243 \\
\hline ROP & $0(0.0)$ & 1.115 & $1.039-1.198$ & 0.286 \\
\hline Pulmonary hypertension & $1(11.1)$ & 1.250 & $0.138-11.307$ & 0.842 \\
\hline Hyperglycemia & $2(22.2)$ & 2.000 & $0.368-10.879$ & 0.415 \\
\hline
\end{tabular}

Note: GIR, glucose infusion rate $(\mathrm{mg} / \mathrm{kg} / \mathrm{min}) ; \mathrm{RDS}$, respiratory distress syndrome; NEC, necrotizing enterocolitis; ROP, retinopathy of prematurity; $\mathrm{OR}$, odds ratio; $\mathrm{Cl}$, confidence interval; Group I, the GIR usage of $5-<7 \mathrm{~g} / \mathrm{kg} /$ day; Group II, the GIR usage of 7-13 g/kg/day; Group III, the GIR usage of $>13-15 \mathrm{~g} / \mathrm{kg} / \mathrm{day}$

*Significant $p$-value $<0.05$

glucose infusion is necessary to prevent early postnatal hypoglycemia as a result of the interruption of the maternal-fetal glucose transfer and the low glycogen reserves of preterm infants. Another study demonstrated that to prevent hypoglycemia and meet the energy requirements needed for growth, it is recommended to start parenteral nutrition in preterm infants immediately after birth with a glucose intake at least equal to the basal glucose turnover rate for infants, $4-7 \mathrm{mg} / \mathrm{kg} / \mathrm{min}$ [33]. Gluconeogenesis is the major pathway for glucose

Table $\mathbf{4}$ The result of multivariate logistic regression analysis

\begin{tabular}{llllll}
\hline GIR & Neonatal Morbidity & AOR & $\mathbf{9 5 \%} \mathbf{C l}$ for the AOR & P \\
\hline Group I & Hypoglycemia, n (\%) & & & & \\
& $9(42.9)$ & 4.000 & 1.384 & 11.565 & $0.010^{*}$ \\
& Sepsis, n (\%) & & & & \\
& $1(4.8)$ & 0.096 & 0.012 & 0.757 & $0.026^{*}$ \\
\hline
\end{tabular}

GIR, glucose infusion rate; Group I, the GIR usage of $5-<7 \mathrm{~g} / \mathrm{kg} /$ day $\mathrm{AOR}$, adjusted odds ratio; $\mathrm{Cl}$, confidence interval

*A P value $<0.05$ was accepted as the independent variable
Table 5 Risk Factor for Mortality $(n=17)$

\begin{tabular}{|c|c|c|c|c|}
\hline Variables & n (\%) & OR & $95 \% \mathrm{Cl}$ & $p$ \\
\hline Group I & $1(5.9)$ & 0.271 & $0.033-2.205$ & 0.194 \\
\hline Group ॥ & $13(76.5)$ & 1.565 & $0.465-5.271$ & 0.467 \\
\hline Group III & $3(17.6)$ & 2.643 & $0.590-11.833$ & 0.190 \\
\hline RDS & $14(82.4)$ & 5.423 & $1.446-20.346$ & $0.006^{*}$ \\
\hline NEC & $2(11.8)$ & 1.390 & $0.263-7.363$ & 0.691 \\
\hline Sepsis & $9(52.9)$ & 3.875 & $1.306-11.495$ & $0.011^{*}$ \\
\hline ROP & $1(5.9)$ & 0.493 & $0.058-4.174$ & 0.509 \\
\hline Pulmonary hypertension & $3(17.6)$ & 2.643 & $0.590-11.833$ & 0.190 \\
\hline Hypoglycemia & $5(29.4)$ & 1.667 & $0.513-5.415$ & 0.392 \\
\hline Hyperglycemia & $2(11.8)$ & 0.836 & $0.168-4.171$ & 0.827 \\
\hline
\end{tabular}

production in preterm infants; however, there is a delay in gluconeogenesis in the early days after the birth of preterm infants. Combined with low glycogen stores, this puts preterm infants at risk of hypoglycemia if they do not immediately receive exogenous glucose [34].

This study found that a GIR usage of $5-<7 \mathrm{~g} / \mathrm{kg} /$ day significantly reduced the risk of sepsis. These findings are consistent with a study by Tottman et al. which reported that a lower glucose administration reduced the risk of sepsis $(10.1 \mathrm{~g} / \mathrm{kg} /$ day versus $12.1 \mathrm{~g} / \mathrm{kg} /$ day, $P=$ 0.68) [12]. Other studies reported that administration of higher glucose increased the risk of sepsis [13, 31]. The explanation is that the subjects in that study were extremely low birth weight infants (gestational age of 30 weeks and birth weight of $1000 \mathrm{~g}$ ), meanwhile, the majority of the infants recruited in this study were latepreterm infants with birth weights of $1500-<2500 \mathrm{~g}$. The late-preterm infants had a more mature digestive tract hence they did not receive $\mathrm{PN}$ for long, consequently such infants received less PN volume with a lower GIR. Based on our result, we suggest that further research is needed to further define glucose administration in parenteral nutrition in extremely low birth weight infants, particularly in a developing country.

Table 6 The multivariate logistic regression analysis for mortality $(n=17)$

\begin{tabular}{lllll}
\hline Variable & $\begin{array}{l}\text { Mortality } \\
\mathbf{n}(\%)\end{array}$ & AOR & $\mathbf{9 5 \% ~ C l ~ f o r ~ A O R ~}$ & $\boldsymbol{p}$ \\
\hline Group I & $1(5.9)$ & 0.189 & $1.023-1.563$ & 0.122 \\
RDS & $14(82.4)$ & 5.404 & $1.421-20.548$ & $0.013^{*}$ \\
\hline
\end{tabular}

Note: Group I, the glucose infusion rate usage of $5-<7 \mathrm{~g} / \mathrm{kg} / \mathrm{day}$; RDS, respiratory distress syndrome; $\mathrm{AOR}$, adjusted odds ratio; $\mathrm{Cl}$, confidence interval; *A $p$-value $<0.05$ was accepted as independent variables 
The most common cause of hyperglycemia in the postnatal period is the high intake of glucose, in this case, the use of GIR $>10 \mathrm{mg} / \mathrm{kg} / \mathrm{min}$ [35]. Earlyaggressive parenteral nutrition, which allows an enhance in glucose supply, potentially increases the risk of hyperglycemia [13]. Based on our protocol, the highest limit of the GIR we use is $15 \mathrm{~g} / \mathrm{kg} /$ day. In case the BG levels $>150 \mathrm{mg} / \mathrm{dL}$, we reduced the rate of glucose infusion by $1-2 \mathrm{~g} / \mathrm{kg} /$ day until BG levels return to normal levels; however, insulin is not a routine therapy in our NICU. We found that a GIR usage of $>13-15 \mathrm{~g} / \mathrm{kg} /$ day did not increase the risk of hyperglycemia. We also found that using a GIR of either $7-13 \mathrm{~g} / \mathrm{kg} /$ day or $>13-15 \mathrm{~g} / \mathrm{kg} /$ day did not increase the risk of mortality. The occurrence of hyperglycemia at high GIR is partially due to increased catecholamine concentrations as a consequence of unstable and stressful conditions [36]. Current guidelines for PN practice in preterm infants recommended the early administration of amino acids and lipids. Evidence demonstrated that the introduction of amino acids within $4 \mathrm{~h}$ after birth diminished insulin-treated hyperglycemia incidence in preterm infants [37]. Our parenteral nutrition contains amino acids and lipids as macronutrients which we delivered within $24 \mathrm{~h}$ of birth to our preterm infants. The use of amino acids and lipids immediately after birth can improve glucose homeostasis, thereby reducing the risk of hyperglycemia.

This study found that RDS and sepsis significantly increased the risk of mortality, meanwhile, neither hyperglycemia nor hypoglycemia increased the risk of mortality. Based on the results of our study, hyperglycemia or hypoglycemia alone was not sufficient to affect mortality; however, mortality was related to the morbidity associated with both glucose imbalance [36].

This study had a few limitations that need to be considered. First, we did not quantify the amount of enteral nutrition. A previous study showed that the administration of enteral nutrition assisted glycaemic control [12]. Second, we did not perform urine glucose routinely. However, glycosuria is not a reliable biomarker for assessing blood glucose levels [38, 39]. Another limitation is that the group of preterm infants with birth weight < $1500 \mathrm{~g}$ or gestational age $<30$ weeks as the main target of $\mathrm{PN}$ in preterm infants has a small portion in this study. Further studies are required to investigate what is the optimal GIR for such extremely low birth weight infants; however, the PN practice will continue to evolve.

\section{Conclusion}

We found in this study that the GIR usage of $<7 \mathrm{~g} / \mathrm{kg} /$ day in $\mathrm{PN}$ in the first week of life administered to preterm infants was an independent variable in increasing hypoglycemia, but in contrast, reducing the risk of sepsis. However, extremely low birth weight infants require further research.

\section{Acknowledgments}

We wish to thank all staff in the Division of Neonatology and Pediatric Ward, the doctors, the nurses at the Dr. Soetomo General Academic Hospital, and the Post-Graduate Doctoral Program Faculty of Medicine Universitas Airlangga, Surabaya, Indonesia, for granting us the permission and necessary support to conduct this research. We would also like to thank Fis Citra Ariyanto who helped in the editing process.

\section{Authors' contributions}

Dina Angelika: Conceptualization, Methodology, Data curation, Resources, Writing-original draft. Risa Etika: Visualization, Supervision, Investigating. Martono Tri Utomo: Visualization, Supervision, Investigating. Setya Mirha: resource, data curation, formal analysis. Kartika Darma Handayani: Software, Resources, Data curation, Validation. I Dewa Gede Ugrasena: Methodology, Formal analysis, Writing-review, and editing. All authors read and approved the final manuscript.

\section{Funding}

This study did not receive any specific grants from any funding agency in the public, commercial, and not-for-profit sectors.

\section{Availability of data and materials}

All data generated or analyzed during this study are included in this published article and its supplementary information files.

\section{Declarations}

Ethics approval and consent to participate

This study was approved by the Ethical Committee in Health Research at the Dr. Soetomo General Academic Hospital (Reference number. 0203/KEPK/V/ 2018). Informed and signed consent was acquired from the parents or authorized representatives of each infant.

\section{Consent for publication}

Not applicable.

\section{Competing interests}

The authors declare that there were no conflicting interests.

\section{Author details}

${ }^{1}$ Faculty of Medicine, Universitas Airlangga - Dr. Soetomo General Academic Hospital, Surabaya, Indonesia. ${ }^{2}$ Department of Child Health, Faculty of Medicine, Universitas Airlangga - Dr. Soetomo General Academic Hospital, Jl. Mayjend Prof. Dr. Moestopo No. 6-8, Airlangga, Gubeng, Surabaya, East Java 60286, Indonesia. ${ }^{3}$ Department of Child Health, Faculty of Medicine,

Universitas Brawijaya - Saiful Anwar General Hospital, Malang, Indonesia.

Received: 22 April 2021 Accepted: 4 October 2021

Published online: 04 November 2021

\section{References}

1. De Curtis M, Rigo J. The nutrition of preterm infants. Early Hum Dev. 2012; 88(Suppl 1):S5-7. https://doi.org/10.1016/j.earlhumdev.2011.12.020.

2. Embleton ND, Simmer K. Practice of parenteral nutrition in VLBW and ELBW infants. World Rev Nutr Diet. 2014;110:177-89. https://doi.org/10.1159/0003 58466.

3. Johnson PJ. Review of macronutrients in parenteral nutrition for neonatal intensive care population. NN. 2014;33(1):29-34. https://doi.org/10.1891/073 0-0832.33.1.29.

4. Adamkin DH, Radmacher PG. Current trends and future challenges in neonatal parenteral nutrition. J Neonatal-Perinatal Med. 2014;7(3):157-64. https://doi.org/10.3233/npm-14814008.

5. Hsiao CC, Tsai ML, Chen CC, Lin HC. Early optimal nutrition improves neurodevelopmental outcomes for very preterm infants. Nutr Rev. 2014; 72(8):532-40. https://doi.org/10.1111/nure.12110.

6. Mitanchez D. Glucose regulation in preterm newborn infants. Horm Res. 2007;68(6):265-71. https://doi.org/10.1159/000104174.

7. Mesotten D, Joosten K, van Kempen A, Verbruggen S. ESPGHAN/ESPEN/ ESPR/CSPEN guidelines on pediatric parenteral nutrition: Carbohydrates. Cli Nutr (Edinburgh, Scotland). 2018;37(6 Pt B):2337-43. https://doi.org/10.1016/ j.clnu.2018.06.947. 
8. Stark J, Simma B, Blassnig-Ezeh A. Incidence of hypoglycemia in newborn infants identified as at risk. J Maternal-Fetal Neonatal Med. 2020;33(18): 3091-6. https://doi.org/10.1080/14767058.2019.1568985.

9. ElHassan NO, Kaiser JR. Parenteral Nutrition in the Neonatal Intensive Care Unit. 2011;12(3):e130-e40. doi: https://doi.org/10.1542/neo.12-3-e130\%J NeoReviews.

10. Velaphi S. Nutritional requirements and parenteral nutrition in preterm infants. South Afr J Clin Nutr. 2011;24(sup3):27-31. https://doi.org/10.1080/1 6070658.2011.11734377.

11. Thureen PJ. Early aggressive nutrition in very preterm infants. Nestle Nutrition workshop series Paediatric programme. 2007;59:193-204; discussion -8. doi: https://doi.org/10.1159/000098536.

12. Tottman AC, Bloomfield FH, Cormack BE, Harding JE, Mohd Slim MA, Weston AF, et al. Relationships between early nutrition and blood glucose concentrations in very preterm infants. J Pediatr Gastroenterol Nutr. 2018; 66(6):960-6. https://doi.org/10.1097/mpg.0000000000001929.

13. Stensvold HJ, Strommen K, Lang AM, Abrahamsen TG, Steen EK, Pripp AH, et al. Early enhanced parenteral nutrition, hyperglycemia, and death among extremely low-birth-weight infants. JAMA Pediatr. 2015;169(11):1003-10. https://doi.org/10.1001/jamapediatrics.2015.1667.

14. Galderisi A, Facchinetti A, Steil GM, Ortiz-Rubio P, Cavallin F, Tamborlane W, et al. Continuous Glucose Monitoring in Very Preterm Infants: A Randomized Controlled Trial. Pediatrics. 2017;140(4):e20171162. https://doi. org/10.1542/peds.2017-1162

15. Sabzehei MK, Afjeh SA, Shakiba M, Alizadeh P, Shamshiri AR, Esmaili F. Hyperglycemia in VLBW infants; incidence, risk factors and outcome. Arch Iran Med. 2014;17(6):429-34. 014176/AIM.0010.

16. Mitchell NA, Grimbly C, Rosolowsky ET, O'Reilly M, Yaskina M, Cheung PY, et al. Incidence and risk factors for hypoglycemia during fetal-to-neonatal transition in premature infants. Front Pediatr. 2020;8:34. https://doi.org/10.33 89/fped.2020.00034.

17. Beardsall K, Vanhaesebrouck S, Ogilvy-Stuart AL, Vanhole C, Palmer CR, Ong $K$, et al. Prevalence and determinants of hyperglycemia in very low birth weight infants: cohort analyses of the NIRTURE study. J Pediatr. 2010;157(5): 715-9.e1-3. https://doi.org/10.1016/j.jpeds.2010.04.032.

18. Mohamed S, Murray JC, Dagle JM, Colaizy T. Hyperglycemia as a risk factor for the development of retinopathy of prematurity. BMC Pediatr. 2013;13:78. https://doi.org/10.1186/1471-2431-13-78.

19. Mohsen AHA, Amin AS. Risk factors and outcomes of persistent pulmonary hypertension of the newborn in neonatal intensive care unit of Al-minya university hospital in Egypt. Journal of clinical neonatology. 2013;2(2):78-82. https://doi.org/10.4103/2249-4847.116406.

20. Arsenault D, Brenn M, Kim S, Gura K, Compher C, Simpser E, et al. A.S.P.E.N. clinical guidelines: hyperglycemia and hypoglycemia in the neonate receiving parenteral nutrition. JPEN J Parenter Enteral Nutr. 2012;36(1):81-95. https://doi.org/10.1177/0148607111418980.

21. Rozance PJ, Hay WW. Neonatal Hyperglycemia. 2010;11(11):e632-e9. doi: https://doi.org/10.1542/neo.11-11-e632\%J NeoReviews.

22. Hulley SB, Cummings SR, Browner WS, Grady DG, Newman TB. Designing clinical research fourth edition. Philadelphia: Lippincot Williams \& Wilkins; 2013.

23. Eichenwald EC. Apnea of Prematurity. Pediatrics. 2016;137(1):e20153757. https://doi.org/10.1542/peds.2015-3757

24. Liu M-Y, Chen Y-Y, Hu S-H, Chen Y-K, Chang S-J. The Influence of Aggressive Parenteral Nutrition to Preterm and Very Low Birth Weight Infants. Glob Pediatr Health. 2015;2:2333794X14567192-2333794X. https://doi.org/10.11 77/2333794X14567192

25. Tomsits E, Pataki M, Tölgyesi A, Fekete G, Rischak K, Szollár L. Safety and efficacy of a lipid emulsion containing a mixture of soybean oil, mediumchain triglycerides, olive oil, and fish oil: a randomised, double-blind clinical trial in premature infants requiring parenteral nutrition. J Pediatr Gastroenterol Nutr. 2010;51(4):514-21. https://doi.org/10.1097/MPG.0b013 e3181de210c

26. Koletzko B, Goulet O, Hunt J, Krohn K, Shamir R. 1. Guidelines on Paediatric Parenteral Nutrition of the European Society of Paediatric Gastroenterology, Hepatology and Nutrition (ESPGHAN) and the European Society for Clinical Nutrition and Metabolism (ESPEN), Supported by the European Society of Paediatric Research (ESPR). J Pediatr Gastroenterol Nutr. 2005:41(Suppl 2):S187. https://doi.org/10.1097/01.mpg.0000181841.07090.f4.

27. Su BH. Optimizing nutrition in preterm infants. Pediatrics and neonatology 2014;55(1):5-13. https://doi.org/10.1016/j.pedneo.2013.07.003.
28. Rubarth $L B$, Quinn J. Respiratory development and respiratory distress syndrome. Neonatal network : NN. 2015;34(4):231-8. https://doi.org/10.1891/ 0730-0832.34.4.231.

29. Wertheimer F, Arcinue R, Niklas V. Necrotizing enterocolitis: enhancing awareness for the general practitioner. Pediatr Rev. 2019;40(10):517-27. https://doi.org/10.1542/pir.2017-0338.

30. Shane AL, Sánchez PJ, Stoll BJ. Neonatal sepsis. Lancet (London, England). 2017:390(10104):1770-80. https://doi.org/10.1016/s0140-6736(17)31002-4.

31. Dinerstein $A$, Nieto RM, Solana CL, Perez GP, Otheguy LE, Larguia AM. Early and aggressive nutritional strategy (parenteral and enteral) decreases postnatal growth failure in very low birth weight infants. J Perinatol: official journal of the California Perinatal Association. 2006;26(7):436-42. https://doi. org/10.1038/sj.jp.7211539.

32. Guellec I, Gascoin G, Beuchee A, Boubred F, Tourneux P, Ramful D, et al. Biological impact of recent guidelines on parenteral nutrition in preterm infants. J Pediatr Gastroenterol Nutr. 2015;61(6):605-9. https://doi.org/10.1 097/mpg.0000000000000898.

33. Taylor SN, Kiger J, Finch C, Bizal D. Fluid, electrolytes, and nutrition: minutes matter. Advances in neonatal care : official journal of the National Association of Neonatal Nurses. 2010;10(5):248-55. https://doi.org/10.1097/A NC.0b013e3181f0823e

34. Sharma A, Davis A, Shekhawat PS. Hypoglycemia in the preterm neonate: etiopathogenesis, diagnosis, management and long-term outcomes. Transl Pediatr. 2017:6(4):335-48. https://doi.org/10.21037/tp.2017.10.06.

35. Decaro MH, Vain NE. Hyperglycaemia in preterm neonates: what to know, what to do. Early Hum Dev. 2011;87(Suppl 1):S19-22. https://doi.org/10.101 6/j.earlhumdev.2011.01.005

36. Hay WW, Jr. Aggressive Nutrition of the Preterm Infant. Curr Pediatr Rep. 2013;1(4):https://doi.org/10.1007/s40124-013-0026-4. doi: https://doi.org/10.1 007/s40124-013-0026-4.

37. Mahaveer A, Grime C, Morgan C. Increasing early protein intake is associated with a reduction in insulin-treated hyperglycemia in very preterm infants. Nutr Clin Pract. 2012;27(3):399-405. https://doi.org/10.1177/ 0884533612438730.

38. Falcão MC, Leone CR, Ramos JL. Is glycosuria a reliable indicator of adequacy of glucose infusion rate in preterm infants? Sao Paulo medical journal = Revista paulista de medicina. 1999;117(1):19-24. https://doi.org/1 0.1590/s1516-31801999000100004.

39. Jagła M, Szymońska I, Starzec K, Kwinta P. Preterm glycosuria - new data from a continuous glucose monitoring system. Neonatology. 2018;114(1): 87-92. https://doi.org/10.1159/000487846.

\section{Publisher's Note}

Springer Nature remains neutral with regard to jurisdictional claims in published maps and institutional affiliations.

Ready to submit your research? Choose BMC and benefit from:

- fast, convenient online submission

- thorough peer review by experienced researchers in your field

- rapid publication on acceptance

- support for research data, including large and complex data types

- gold Open Access which fosters wider collaboration and increased citations

- maximum visibility for your research: over $100 \mathrm{M}$ website views per year

At $\mathrm{BMC}$, research is always in progress.

Learn more biomedcentral.com/submissions 